\title{
Construction Strategies of MOOC Quality Evaluation Based on Postmodernism Perspective
}

\author{
Hui Zhang ${ }^{1,2}$ a , Pan $\mathrm{Du}^{1, \mathrm{~b}^{*}}$ and Jiping $\mathrm{Li}^{3, \mathrm{c}}$ \\ 1School of Economics and Management, Hubei Engineering University, Xiaogan, Hubei, 432100, \\ China \\ 2Research Center of Hubei Micro \& small Enterprises' Development, Hubei Engineering University, \\ Xiaogan, Hubei, 432100, China \\ 3School of Computer and Information Science, Hubei Engineering University, Xiaogan, Hubei, \\ 432100, China \\ azhang_if@126.com,b184011531@qq.com,c735670934@qq.com
}

Keywords: Postmodern curriculum evaluation; MOOC; Open pluralism; Curriculum value

\begin{abstract}
MOOC (Massive Open Online Courses) is an emerging educational mode that enables vast learners to easily access massive learning resources through the Internet. The MOOC course is characterized by openness, interaction, sharing and personalization. Therefore, MOOC curriculum evaluation should be combined with reality, and make a multi-dimensional and dynamic evaluation. The postmodern curriculum evaluation theory advocates the concept of "openness and diversity, consultation and dialogue" which is in line with the characteristics of MOOC curriculum. Based on the postmodern perspective, this paper discusses MOOC from five aspects: the purpose of evaluation, the content of evaluation, the subject of evaluation, the evaluation criteria and the method of evaluation.
\end{abstract}

\section{Introduction}

MOOC (Massive Open Online Courses), translated into Chinese as "Mu class" (large-scale open network courses), is a new education mode developing rapidly in recent years. Taking the MOOC of China University as an example, by the end of November 16, 2017, there were 146 platform cooperative colleges and universities, which launched 1016 courses and covered a number of subjects. The sharing of teaching based on the Internet is in line with the trend of the ubiquitous Internet, fragmentation of personal time, and the popularity of shared ideas. MOOC provides everyone with free access to resources from prestigious universities through the web, and allows everyone to learn from anywhere by using multiple devices. From the above characteristics, many famous universities at home and abroad actively involved in the construction of MOOC platform, and launched a large number of online courses. In the face of a large number of MOOC, how to assess the quality? How to help learners to obtain better learning resources? How to regulate and promote the construction of MOOC? Domestic and foreign scholars put forward different evaluation systems. However, MOOC has not yet formed a unified evaluation system due to its short development time and its rapid development. Based on this, this paper analyzes the characteristics of MOOC curriculum, and constructs the MOOC curriculum evaluation system from the perspective of post-modern curriculum evaluation theory.

\section{Analysis of Current Research Status at Home and Abroad}

The rise time of MOOC is not long, and its development is affected by a series of factors such as content resources, network bandwidth and incentive mechanism, so that there are many different opinions on its evaluation research. MOOC assessment is a complex task. It requires multiple perspectives to evaluate and includes a combination of performance monitoring and evaluation system and adaptation and emergency assessment survey framework. Different standards and tools should be considered in different frameworks[1]. In Europe where MOOC grew earlier, different 
assessment orientations also emerged because of the differences in country-based assessment of the quality of education. For example, the Federation of European Distance Education Universities paid close attention to MOOC's Open Education Quality Label. Spain's MOOC education quality evaluation considered more factors, and they were more concerned about the construction of comprehensive evaluation index system. The German MOOC design quality evaluation standard selects the local or overall evaluation criteria according to the purpose of evaluation. The evaluation method highlights the subjective status of teachers and learners, and the evaluation link strengthens the quality control[2]. The evaluation of MOOC quality is also supported by some empirical data. We take "MOOC College" community forum as data source, use text mining technology to process and analyze it, so as to get some evaluation index of some courses. At the same time, we combine the existing curriculum evaluation standards, set up the MOOC evaluation index system, and use the similarity measure based on Vague sets to establish the MOOC evaluation model[3]. The model is more objective and realistic, which is good for MOOC learners to determine the quality of the course. At the same time, the Chinese education authorities have also formulated relevant norms. National Education Ministry of Education Information Standardization Committee developed a "Network Course Evaluation Specification (CELTS-22)". On the basis of this, the related research explanatorily established the MOOC quality evaluation index system which includes three first-level indicators (course content, instructional design, learning support) and 26 second-level indicators, and established the weight of indicators by AHP. By selecting one course on each of the three major MOOC platforms in China, the evaluation system was used to evaluate the practice and achieve better results[4].

In summary, scholars have studied the quality of MOOC curriculum from different perspectives, and put forward the corresponding evaluation system, but most of them are based on specific evaluation indicators and measurement techniques, and seldom set up curriculum evaluation system from the perspective of curriculum value. Based on the theoretical perspective of post modern curriculum evaluation and combined with the characteristics of MOOC course, this paper constructs a curriculum evaluation system for MOOC value creation and implementation, so as to provide reference for the development and construction of MOOC curriculum in the future.

\section{The Characteristics of MOOC Course}

Different from the traditional teaching mode of on-the-spot teaching, MOOC spreads the massive teaching resources to every learner of the network terminal through the Internet, which also makes the MOOC course have distinct characteristics. Characteristics are mainly reflected in the following aspects:

Multimedia. Teaching information is organized by a variety of media such as graphic images, sound, animation, video, etc. The learning process as well as exams and homework assignments is all completed through the Internet, which enables learners to receive information through a full range of senses so as to receive better teaching effect and experience the convenience of MOOC. However, MOOC possesses certain thresholds for those who lack basic network literacy or network equipment.

Openness and Interactivity. MOOC is free and open to global learners. Learners can access the curriculum resources and study online at anytime and anywhere. Interaction is embodied in human-computer interaction, interaction between teachers and students, and the interaction between learners.

Individualization. MOOC meets the learning needs of learners' mobile learning and fragmentation. Meanwhile, due to the nonlinear characteristics of curriculum content, learners can combine their own situations to make personalized learning plans. This will greatly enhance learners' autonomy.

Sharing. MOOC integrates a large number of network tools and social platforms (such as We Chat, QQ, public mail), all resources on the Internet are learners' references and learning materials, and learners can also share MOOC information to their friends circles. This makes MOOC a huge collection of network resources, and can also spread to more learners faster. 


\section{The formulation of the MOOC Curriculum Evaluation Scheme}

The Choice of Evaluation Theory. The openness and individuality of the MOOC curriculum determine that the effectiveness of the curriculum depends on the learner's initiative and participation. The goal of the course is to promote learner learning and equity in education. Therefore, we choose Doll, W.E's theory of postmodern curriculum as the evaluation theory of MOOC course. Doll.W.E, in his book Postmodern Curriculum, clearly defined the concept of postmodern curriculum evaluation in 1993, arguing that "the evaluation should be the coordinating process with the aim of transformation in a common context. It should be used as a kind of feedback[5]". Post modern curriculum evaluation advocates the creation of open and diversified evaluation culture atmosphere, emphasizing the interaction, negotiation, construction and change of course participants. It has the characteristics of openness, situationality, process and development. In such an evaluation system, the existence of individual differences has been respected, and the subjectivity of exploring the unknown has been released.

The Construction of the Evaluation System. The open, shared and personalized features of the MOOC course are closely related to the concept of "open pluralism, negotiation and dialogue" advocated by the theory of post-modern curriculum evaluation. Based on this, this article tries to explore the construction strategy of MOOC curriculum evaluation system from the perspective of post-modern from five aspects: the purpose of evaluation, the content of evaluation, the subject of evaluation, the evaluation criteria and the evaluation methods.

The first one is the purpose of evaluation. Post-modern curriculum evaluation system not only focuses on learner's knowledge acquisition, but also on learners' methods, processes, emotions, attitudes and values. So the purpose of MOOC curriculum evaluation from the perspective of post-modernism is multidimensional and developmental, and it mainly includes the following four aspects: (1) Knowledge acquisition, that is, the level of knowledge and professional skills acquired by learners can be measured through the classroom and test scores. (2) The mastery of the method. That is whether the messenger learns the professional learning method, whether the learning method is effective and whether the original method can be improved, so as to achieve a better learning effect. (3) The emotional attitude, that is a series of affective factors that affect the learning effect such as interest, motivation, concentration and autonomy of the learner in the learning process. (4) The value, which is the highest level of influence, that is, learners learn the value of the course through the MOOC course and discover and experience its short-term or long-term impact on their own values.

The second one is the content of evaluation. Postmodern curriculum evaluation breaks down the mechanical thinking of modern curriculum evaluation and regards people as an organic whole with harmonious development of body and mind. For the evaluation of MOOC curriculum, the course itself, teachers, learners and teaching process should also be conducted with an open mind and a multi-level, multi-stage overall evaluation. First is the course itself. The course itself is a developing organism, and the purpose of the course evaluation is to discover the value of the course. Different from the activity of recognizing the effect of the course, the course evaluation is a kind of understanding of the meaning and value of the course activity. A.V. Kelly, a UK on-curricular expert, believes that if we want to make a truly educational assessment of a course, we need to ask about the value of education or education reform, not the teaching methodology. The target-based course evaluation or the teaching-based course evaluation is only relevant to the teacher's effective explanation of the course contents. However, we must not only know whether teachers effectively "impart" the content of the course, but more importantly, whether these courses are worth "teaching"[6]. Second is teachers' evaluation. Teachers are the important objects of course evaluation. The MOOC platform provides teachers with a broad stage to impart their professional knowledge and personal charisma to learners all over the world. Comments from the comment area and the MOOC team's after-school teacher evaluation questionnaire also allow the instructor to hear voices from learners all over the world. The MOOC curriculum evaluation system should respect every teacher's personality and teaching style, and evaluate it comprehensively through teacher's teaching level, teaching quality, personal accomplishment, teaching methods, curriculum innovation 
and student interaction. Encourage teachers to develop themselves and improve their teaching level and personal quality in many ways. Third is learner evaluation. Postmodern curriculum evaluation is opposed to single and narrow evaluation content. It advocates that measurement should not only focus on test scores, but also focus on the learner as a unique individual, and pay attention to their method using in the learning process, their emotional attitude and the formation of values. It is believed that such a growth type of evaluation content can stimulate the learning enthusiasm of the learners and promote the all-round development of the learners. Fourth is the teaching process. The teaching process includes the teacher's teaching process, the learner's learning process, the teacher-student interaction process and the interaction process between the learners. In this process, we should not only pay attention to the goal of teaching, but also pay attention to the influence of teaching process on the development and growth of teachers and learners.

The third one is the subject of evaluation. Postmodernism points out that the existence of "human" is a kind of relationship, and "ego" is defined by others, in which an individual is an equal and friendly relationship. Everyone has the right to speak freely, while respecting others is seen as a virtue. It is mapped to the MOOC course evaluation and that is to advocate a multi party consultation evaluation system. The main body of evaluation includes all stakeholders of MOOC course, teachers, learners, production team, curriculum experts and other different levels and different interests of staff. Moreover, there is an "equal and consultative" relationship among different participants, and all evaluations are for the improvement of curriculum and the comprehensive development of people. In such a multi-participatory consultation and evaluation system, there is no "expert" or "authority" firmly holding the right to speak, every individual is encouraged to give his own voice and embody a spirit of education based on "people-oriented and all-round development".

The fourth one is the evaluation criteria. In the field of postmodernism, curriculum is an open and complex system and also a process of multiple changes. During the course evaluation, we should pay attention to the development of multiple subjects such as the curriculum itself, teachers and learners, and promote the multi-party value proposition and stakeholder interaction and consultation, so in the MOOC curriculum evaluation system from a post-modern perspective, we should establish a flexible evaluation criterion of multiple changes. Specifically, for the evaluation of "people" such as teachers and learners, it is necessary to recognize the difference between people and respect each person's uniqueness and development. We can't use a ruler to measure all people. We should take full account of everyone's environment and personal factors. Then we set different evaluation criteria to promote everyone's all-round and harmonious development. For the evaluation of different courses, we must grasp the development characteristics and levels of different disciplines, and consider the development elements of each course in reality so as to guide the curriculum to be constantly improved to meet the individual needs of learners.

The fifth one is the evaluation method. MOOC learning is a personalized and interactive new learning way, which makes traditional quantitative evaluation methods such as examination and test fail to evaluate MOOC course effectively. Qualitative analysis is based on systematic analysis, interviews, surveys, literature analysis and other methods to grasp the construction and interpretation of individual uniqueness and behavioral meaning. This method is consistent with the openness and situational content of post modern curriculum evaluation. Each evaluation method has its own advantages and disadvantages. In the concrete application, the quantitative evaluation and the qualitative evaluation method can be combined to complement each other according to the actual situation.

The contents of the above five aspects are integrated, and the MOOC course evaluation model(Figure 1) is obtained. 


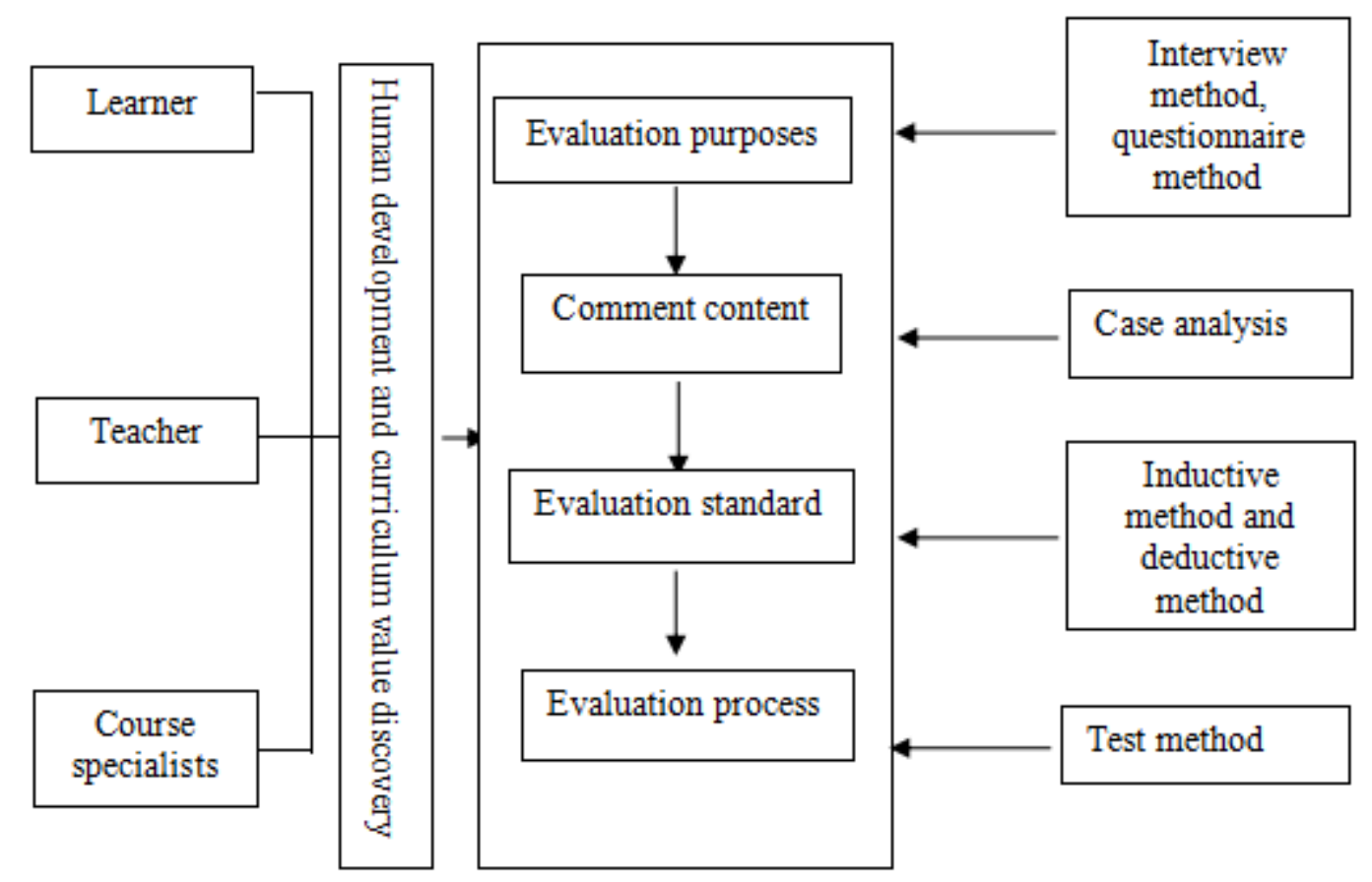

Figure 1. The evaluation model of MOOC course in the perspective of post-modern curriculum

\section{Conclusions}

MOOC curriculum evaluation system based on postmodern perspective is the thinking and strategic conception of the existing MOOC curriculum evaluation research. The postmodern curriculum evaluation theory and the characteristics of MOOC curriculum both have open and diverse elements, at the same time, the explanation of post-modern curriculum evaluation theory "the essence of curriculum evaluation is a kind of value judgment" is very fit with the current curriculum construction and it is an important direction for MOOC curriculum evaluation research in the future.

\section{Acknowledgements}

Fund project: The Research Project of Provincial Teaching Reform of Universities in Hubei(2015400); School Level Teaching Team Project of Hubei Engineering College in 2015: School enterprise cooperation teaching team in marketing major; Key Topics of Hubei Education Science Planning in 2015(2015GA038).

\section{References}

[1] Chapman S A, Goodman S, Jawitz J, et al. A strategy for monitoring and evaluating massive open online courses[J]. Evaluation and Program Planning, 2016(57):55-63.

[2] L.Liu, Z.M.Liu and Y.Z.Luo: The Evaluation Method and Enlightenment of European MOOC Education Quality[J], Open Education Research, 2015(05):57-65.(In Chinese)

[3] K.Yao, S.Z.Li, Y.H.Li, etc: Research on MOOC Evaluation Model[J], Fudan Education Forum, 2017(03):65-71.(In Chinese)

[4] X.S.Tong and X.J.Jia: Research on the Construction of MOOC Quality Evaluation System[J], Distance Education In China, 2017(05):63-71.(In Chinese)

[5] William E.Doll: A Post-Modern Perspective on Curriculum[M], Educational Science Press, 2000.(In Chinese)

[6] Kelly: Curriculum Theory and Practice[M], China Light Industry Press, 2007. 